\title{
Topical 15\% Zinc Sulfate Solution Is an Effective Therapy for Feet Odor*
}

\author{
Khalifa E. Sharquie ${ }^{1 \#}$, Adil A. Noaimi ${ }^{2}$, Saad D. Hameed ${ }^{3}$ \\ ${ }^{1}$ Scientific Council of Dermatology \& Venereology-Iraqi Board for Medical Specializations, Department of Dermatology \& Vene- \\ reology, College of Medicine, University of Baghdad, Baghdad, Iraq; ${ }^{2}$ Head of Department of Dermatology \& Venereology, College \\ of Medicine, University of Baghdad, Baghdad, Iraq; ${ }^{3}$ Department of Dermatology and Venereology, Baghdad Teaching Hospital, \\ Medical City, Baghdad, Iraq. \\ Email: "ksharquie@ymail.com, adilnoaimi@yahoo.com, saadhameed9@yahoo.com
}

Received May $12^{\text {th }}$, 2013; revised June $15^{\text {th }}$, 2013; accepted June $23^{\text {rd }}, 2013$

Copyright (C) 2013 Khalifa E. Sharquie et al. This is an open access article distributed under the Creative Commons Attribution License, which permits unrestricted use, distribution, and reproduction in any medium, provided the original work is properly cited.

\begin{abstract}
Background: Feet odor is a common sociomedical problem that affects the feet of human beings of different etiological factors. Multiple modalities of therapy have been used in the treatment of feet odor. Objective: To evaluate the efficacy and safety of topical 15\% zinc sulfate solution in the treatment of feet odor. Patients and Methods: This single blind, placebo, controlled therapeutic study was conducted at the Department of Dermatology-Baghdad Teaching Hospital, from March 2010 to July 2011. A total of 108 (88 males and 20 females) patients with feet odor were enrolled and were divided into 2 groups: Group A: treated with 15\% zinc sulfate solution. Group B: treated with distilled water as placebo control group. Full history and examination were carried out including all relevant points. Four scoring had been used to assess the severity of odor in patients with bared feet Score 0: no odor, Score 1: mild odor, Score 2: moderate odor and Score 3: severe odor. Zinc sulfate solution $15 \%$ was applied to sole and toe webs once daily for two weeks, three times per week for next two weeks and followed by single application weekly as maintenance after clearance of odor for two months. Patients were seen every two weeks to be examined and to score the odor again and to record side effects. Results: Group A: Fifty patients completed the study, their ages ranged from 8 - $68(33+14.5)$ years, while the duration of the disease ranged from $1-180(7.22+38.24)$ months. The complete clearance of feet odor after two weeks of therapy was $35(70 \%)$ patients which was similar to two months maintenance therapy 35 (70\%) and was highly statistically significant ( $\mathrm{p}$ value $=0.0000001$ ). Group B: Fifty patients received the placebo solution, their ages ranged from $16-75$ $(32.6+13.4)$ years, while the duration of the disease ranged from $1-180(43.7+47.65)$ months. The complete clearance of feet odor was in $1(2 \%)$ patient after two weeks therapy and after two months maintenance therapy. No side effects were recorded. Conclusions: Topical 15\% zinc sulfate solution had an effective therapeutic and prophylactic action against feet odor.
\end{abstract}

Keywords: Feet Odor; Topical; Zinc Sulfate

\section{Introduction}

Feet odor is a common socio-medical problem, its etiopathogenesis is not well elucidated but there are multifactorial agents like sweating, bacterial, fungal infections, shoes and socks [1].

The most common type of bacteria of feet is Brevibacteria which is considered a major cause of feet odor because they ingest dead skin on the feet and, in the process, convert amino acid methionine into methanethiol, which

\footnotetext{
"Disclosure: This study is an independent study and not funded by any drug company.

"Corresponding author.
}

has a sulfuric aroma and cheesy odor. Also Propionibacteria which thrive in the ducts of adolescent and adult sebaceous glands produce propionic acid as result of a breakdown product of amino acids, it has vinegar-like odor. Staphylococcus epidermidis also play a role in feet odor by degradation of leucine present in sweat and changed it to isovaleric acid, which give strong cheesy odor [2].

There are many systemic drugs like anticholinergic (glycopyrrolate) [3] and topical antibacterial drugs like erythromycin, clindamycin and benzoyl peroxide have been used in the treatment of feet odor [4]. Also, topical anti-perspiration agents like aluminum salts and ionto- 
phoresis have been used as therapeutic measures [5,6].

Zinc is an essential trace element that involved in more than 300 metalloenzymes, including the antioxidant enzyme, superoxide dismutase, and it affects their conformity, stability and activity. [7] Zinc sulfate either topical, intralesional or systemic has been used successfully in an effective agent for the treatment of many dermatological problems like acne [8], recurrent aphthous stomatitis [9], cutanous leishmaniasis [10,11], plane warts [12], viral warts [13,14], pityriasis versicolor [15], superficial fungal infections [16]. It works through its different modes of action which are antioxidant, antiviral, antidermatophyte, astringent, immunomodulator and cytotoxic in high concentration [17].

For this reasons the present study was designed to evaluate the efficacy and safety of topical 15\% zinc sulfate solution in the treatment of feet odor.

\section{Patients and Methods}

This single blind placebo controlled therapeutic trial using topical $15 \%$ zinc sulfate solution in the treatment of feet odor was carried out in Department of Dermatology and Venereology, Baghdad Teaching Hospital from March 2010 to July 2011. One hundred eight (88 males and 20 females) patients with feet odor were included in this work. All patients attending the Department of Dermatology and Venereology complained from feet odor were included regardless the age and sex.

\subsection{Exclusion Criteria}

Patients with feet odor with associated tinea pedis, patients had received any therapy for feet odor for last two months, patients with feet complication of diabetes mellitus or atherosclerosis, feet deformity, malformation and patients on immunosuppressive drugs were excluded.

Full history and examination was performed including: age, sex, marital status, residence, social status, job, history of feet odor and family history, duration, type, site, associated with axillary odor, palmoplanter hyperhidrosis, seasonal variations and aggravating factors. Also, history of type of socks, daily change and type of shoes were taken from all cases.

Formal consent was taken from each patient after and full explanation about the nature, course of treatment. The ethical approval was obtained from the Scientific Council of Dermatology and Venereology-Arab Board for Medical Specializations,

Patients were instructed for cleaning and drying the feet and apply the solution to the sole and toe webs as follow: single daily for two weeks, three times per week for other two weeks then single application weekly as maintenance therapy for two months and at each visit the following scoring was done:
Scoring of feet odor (Sharquie's scoring):

Four scoring had been used to assess the severity of odor in patient with bared feet:

Score 0: No odor.

Score 1: Mild odor as it is smelt by patient only when he puts his finger in between toe webs and on his sole.

Score 2: Moderate odor as it is smelt by examining doctor in close contact with patient.

Score 3: Severe odor as the odor is smelt by surroundding people.

This score has been used for first time for such studies.

Follow up of the patients was done every two weeks to assess the response to therapy, to do scoring of odor again and to record any side effects.

\subsection{Preparation and Treatment Plan}

Fifteen percent $(\mathrm{W} / \mathrm{V})$ zinc sulfate solution is prepared by dissolving 15 grams of zinc sulfate crystals $\left(\mathrm{ZnSO}_{4}\right.$ $7 \mathrm{H}_{2} \mathrm{O}=287.54$, by Thomas Bekar India) in $100 \mathrm{ml}$ of distilled water, and kept in clean container at the room temperature of hospital. Patients were asked to apply this preparation on their sole and toe webs using cotton applicator.

Statistical analysis was used in all parameters. Student's $t$ test used for comparison of means by analysis of variance scoring and Chi Square used to compare the changes that result from the treatment.

$P$ value of less than 0.05 is considered to be significant.

\section{Results}

Hundred patients completed the therapy, while 8 patients defaulted for unknown reasons.

Group A: Fifty patients 8 (16\%) females and 42 (84\%) males included in this group. Their ages ranged from 8 68 years with a mean \pm SD of $33 \pm 14.5$ years; while the duration of the disease ranged from 1 - 180 months with a mean \pm SD of $7.22 \pm 38.24$ months.

Seven (14\%) patients had axillary odor in addition to feet odor while 8 (16\%) patients had positive family history of feet odor. History of palmoplanter hyperhydrosis was found in $6(12 \%)$ patients, while 44 (88\%) patients had associated plantar hyperhydrosis. The quality of odor was cheesy in $33(66 \%)$ patients and vinegar odor in 17 (34\%) cases. Twenty one (42\%) of patients had seasonal variation and was worse odor during summer time, while $15(30 \%)$ cases had habit of drying of their feet after washing.

The types of socks were nylon in 20 (40\%), cotton 17 (34\%) and wool 8 (16\%) patients. History of daily change of socks was present in $28(56 \%)$ patients. The types of shoes were leather 33 (66\%), sandal 12 (24\%), and rubber $5(10 \%)$ patients. 
The aggravating factors of feet odor were: hyperhydrosis in $31(62 \%)$, occlusive feet wear in $9(18 \%)$ and nylon socks 9 (18\%) patients (Table 1).

The localization of feet odor in patients as follow: toe webs in 22 (44\%), toe webs and sole in $27(54 \%)$, sole alone in $1(2 \%)$ patient.

Scoring of feet odor before therapy was Score $\mathbf{1}$ in 21

Table 1. Description of study groups with feet odor.

\begin{tabular}{|c|c|c|c|c|}
\hline & \multicolumn{2}{|c|}{ Group (A) } & \multicolumn{2}{|c|}{ Group (B) } \\
\hline & Number & (\%) & Number & $(\%)$ \\
\hline 1 Family history & 8 & 16 & 10 & 20 \\
\hline 2 Axillary odor & 7 & 14 & 12 & 24 \\
\hline 3 Palmoplantar hyperhydrosis & 6 & 12 & 5 & 10 \\
\hline \multicolumn{5}{|l|}{4 Type of odor } \\
\hline Cheesy odor & 33 & 66 & 39 & 78 \\
\hline Vinegar odor & 17 & 34 & 11 & 22 \\
\hline 5 Plantar hyperhydrosis & 44 & 88 & 39 & 78 \\
\hline 6 Season variation & 21 & 42 & 20 & 40 \\
\hline 7 Drying of feet & 15 & 30 & 20 & 40 \\
\hline \multicolumn{5}{|l|}{8 Types of socks } \\
\hline Nylon & 21 & 44 & 24 & 48 \\
\hline Cotton & 17 & 34 & 17 & 34 \\
\hline Wool & 8 & 16 & 5 & 10 \\
\hline Daily changing & 28 & 56 & 26 & 52 \\
\hline \multicolumn{5}{|l|}{9 Types of shoes } \\
\hline Leather & 33 & 66 & 36 & 72 \\
\hline Sandal & 12 & 24 & 11 & 22 \\
\hline Rubber & 5 & 10 & 3 & 6 \\
\hline \multicolumn{5}{|l|}{10 Aggravating factors } \\
\hline Hyperhydrosis & 31 & 62 & 20 & 40 \\
\hline Occlusive footwear & 9 & 18 & 13 & 26 \\
\hline Nylon socks & 9 & 18 & 15 & 30 \\
\hline
\end{tabular}

(42\%) patients, Score 211 (22\%) patients and Score 318 (36\%) patients (Table 2).

Group B: Fifty-three patients with feet odors were included in this study. Fifty patients of feet odor had received the placebo solution (distilled water), consisted from 10 (20\%) females and 40 (80\%) males. Their ages ranged from $16-75$ years with a mean \pm SD of $32.6 \pm$ 13.4 years while the duration of the disease ranged from 1 - 180 months with a mean \pm SD of $43.7 \pm 47.65$ months.

Twelve (24\%) of patients had axillary odor while 10 (20\%) patients had positive family history of feet odor. History of palmoplanter hyperhydrosis was found in 5 (10\%) patients and 39 (78\%) of patients had plantar hyperhydrosis.

The quality of odor was cheesy odor in 39 (78\%) patients and vinegar odor in 11 (22\%) patients. Twenty $(40 \%)$ of patients had seasonal variation with worse odor during summer time. Twenty (40\%) cases had habit drying of feet after washing.

The types of socks were nylon in 24 (48\%) patients, cotton 17 (34\%) and wool 5 (10\%) patients. History of daily change of socks was present in 26 (52\%) patients. The types of shoes were leather in 36 (72\%), sandal 11 (22\%) and rubber 3 (6\%) patients.

The aggravating factors of feet odor were hyperhydrosis in 20 (40\%) patients, occlusive feet wear 13 (26\%) and nylon socks 15 (30\%) patients (Table 1).

Site distribution of feet odor patients was mainly on toe webs 21 (44\%) and sole alone in $3(6 \%)$ patients, toe webs and sole 26 (52\%) patients.

Scoring of feet odor before therapy was Score $\mathbf{1}$ in 22 (44\%) patients, Score 2 in 9 (18\%) patients and Score 3 in $19(38 \%)$ patients (Table 3).

\section{The Clinical Response}

Group A: Scoring of feet odor after 2 weeks of therapy was score 0 in 35 (70\%) patients, score 1 in 12 (24\%) patients, score 2 in 2 (4\%) and score 3: 1 (2\%) patient (Table 2$)(\mathrm{t}$ test $=121.22)(\mathrm{p}$ value $=0.0000001)$.

While scoring of two months maintenance therapy as follow:

Score 1 (21) patients changed into score 0 in 18 (86\%)

Table 2. Scoring of feet odor (Group A) before and after 2 weeks of therapy with topical $15 \%$ zinc sulfate solution.

\begin{tabular}{ccccccccccc}
\hline Scoring before therapy & Scoring & Score 1 (21) & $\%$ & Score 2 (11) & $\%$ & Score 3 (18) & $\%$ & total & $\%$ \\
\hline \multirow{2}{*}{$\begin{array}{c}\text { Scoring after } \\
\text { therapy }\end{array}$} & Score 0 & 18 & 86 & 10 & 91 & 7 & 39 & 35 & 70 \\
& Score 1 & 3 & 14 & 1 & 9 & 8 & 44 & 12 & 24 \\
& Score 2 & 0 & 0 & 0 & 0 & 2 & 11 & 2 & 4 \\
\hline
\end{tabular}

p value $=0.0000001$. 
patients and no change in 3 (14\%) patients.

Score 2 (11) patients changed into score 0 in 10 (91\%) patients and score 1 in 1 (9\%) patient. Score 3 (18) patients changed into score 0 in 7 (39\%) patients, score $\mathbf{1}$ in 8 (44\%) patients; score 2 in 2 (11\%) patients and no change in $1(6 \%)$ patient.

So the response to two months maintenance therapy could be summarized as follow: 35 (70\%) patients had complete clearance which was similar to that after 2 weeks therapy, 11 (22\%) patients with partial clearance and 8 (16\%) patients no change in odor (Table 4 \& Figure 1) $($ Chi square $=74.60$, degree of freedom $=2, \mathrm{p}$ value $=0.0000001$ ) .

No side effects were recorded apart from slight irritation in the early course of treatment which did not require discontinuing the treatment

Group B: Scoring of feet odor after 2 weeks of therapy with distilled water was: score 0 in 1 (2\%) patient, score 1 in 22 (44\%) patients, score 2 in 9 (18\%) patients and score 3 in 18 (36\%) patients (Table 3) (t test $=0.18)(\mathrm{p}$ value $=0.67)$.
While scoring of therapy after two months as follow: Score 1 (22) patients changed into score 0 in 1 (4.5\%) patient and no change in 21 (95.5\%) patients. Score 2 (9) changed into Score 1 in 1 (11\%) patient and no change in 8 (89\%) patients. Score 3 (19) changed into Score 2 in 1 (5\%) patient but no change in 18 (95\%) patients.

So the response to therapy after two months could be summarized as follow: $1(2 \%)$ patient had complete clearance, 2 (4\%) patients with partial clearance and 47 (94\%) patients showed no change in odor (Tables 4-6 \& Figure 1).

\section{Discussion}

There are many etiological factors involved in feet odor like wearing shoes, hyperhydrosis, maceration of skin, proliferation of bacteria and fungal infections. All these factors encourage bacteria species like Staphylococcus epidermidis, Propionibacteria and Brevibacteria to produce volatile short chain free fatty acid which gives characteristic odor like cheesy and vinegar [2].

Table 3. Scoring of feet odor (Group A) after 2 months maintenance therapy with topical 15\% zinc sulfate solution.

\begin{tabular}{ccccccccccc}
\hline Scoring before therapy & Scoring & Score 1 (21) & $\%$ & Score 2 (11) & $\%$ & Score 3 (18) & $\%$ & total & \% \\
\hline & Score 0 & 18 & 86 & 10 & 91 & 7 & 39 & 35 & 70 \\
Scoring after & Score 1 & 3 & 14 & 1 & 9 & 10 & 55.5 & 14 & 28 \\
therapy & Score 2 & 0 & 0 & 0 & 0 & 1 & 5.5 & 1 & 2 \\
& Score 3 & 0 & 0 & 0 & 0 & 0 & 0 & 0 \\
\hline
\end{tabular}

p value $=0.0000001$.

Table 4. Scoring of feet odor (Group B) before and after 2 weeks of therapy with placebo.

\begin{tabular}{cccccccccc}
\hline Scoring before therapy & Scoring & Score 1 (22) & $\%$ & Score 2 (9) & $\%$ & Score 3 (19) & $\%$ & total & $\%$ \\
\hline & Score 0 & 1 & 4.5 & 0 & 0 & 0 & 0 & 1 & 2 \\
\multirow{2}{*}{$\begin{array}{c}\text { Scoring after } \\
\text { therapy }\end{array}$} & Score 1 & 21 & 95.5 & 0 & 0 & 0 & 0 & 21 & 42 \\
& Score 2 & 0 & 0 & 9 & 100 & 0 & 0 & 9 & 18 \\
& Score 3 & 0 & 0 & 0 & 0 & 19 & 100 & 19 \\
\hline
\end{tabular}

p value $=0.99$.

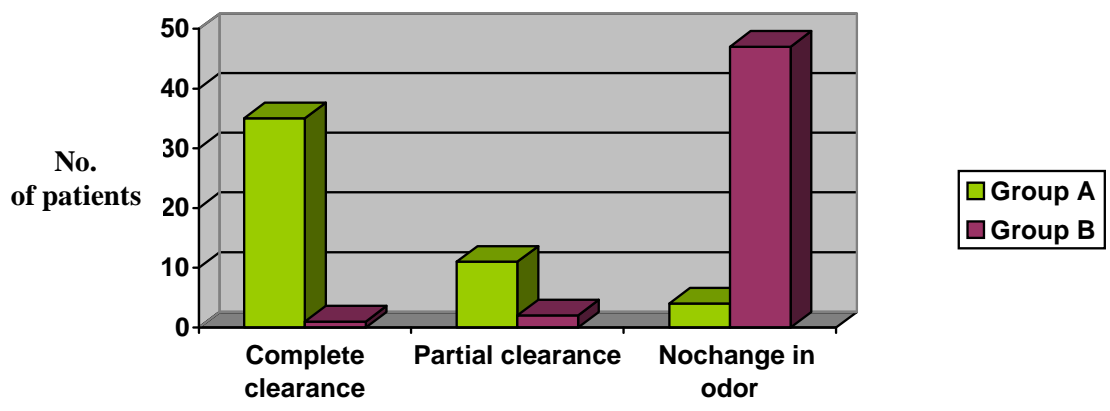

Figure 1. Clinical responses among patients with feet odor following 2 months after therapy in group A and group B. 
Table 5. Scoring of feet odor (Group B) after 2 months maintenance therapy with placebo.

\begin{tabular}{cccccccccc}
\hline Scoring before therapy & Scoring & Score 1 (22) & $\%$ & Score 2 (9) & $\%$ & Score 3 (19) & $\%$ & total & $\%$ \\
\hline \multirow{3}{*}{$\begin{array}{c}\text { Scoring after } \\
\text { therapy }\end{array}$} & Score 0 & 1 & 4.5 & 0 & 0 & 0 & 0 & 1 & 2 \\
& Score 1 & 21 & 95.5 & 1 & 11 & 0 & 0 & 22 & 44 \\
& Score 2 & 0 & 0 & 8 & 89 & 1 & 5 & 9 & 18 \\
& Score 3 & 0 & 0 & 0 & 0 & 18 & 95 & 18 \\
\hline
\end{tabular}

$\mathrm{P}$ value $=0.992$.

Table 6. Showing clinical responses among patients with feet odor following 2 months maintenance therapy.

\begin{tabular}{cccc}
\hline Feet odor & $\begin{array}{c}\text { Complete clearance } \\
\text { No. (\%) }\end{array}$ & $\begin{array}{c}\text { Partial clearance } \\
\text { No. (\%) }\end{array}$ & $\begin{array}{c}\text { No change in } \\
\text { odor No. (\%) }\end{array}$ \\
\hline Group (A) & $35(70 \%)$ & $11(22 \%)$ & $4(8 \%)$ \\
Group (B) & $1(2 \%)$ & $2(4 \%)$ & $47(94 \%)$ \\
\hline
\end{tabular}

$\mathrm{P}$ value $=0.0000001$.

Feet odor is common problem among Iraqi population especially in summer time. This problem practically is seen among people wearing close shoes and specifically among army people. From our daily practice we noticed that feet odor has personal diathesis as some people produce odor while the others not and both of them wear closed shoes and this was confirmed by the present work as family history was positive in $20 \%$ of patients.

There are many therapies which had been used in controlling feet odor, but according to our practice none of these are satisfactory topical antibacterial like erythromycin, clindamycin and benzyl peroxide [4] and topical antiperspirant agents (aluminum salts and iontophoresis) $[5,6]$.

The present work showed that zinc sulfate is an effecttive mode of therapy in treatment of feet odor as $70 \%$ of patients had complete clearance after two weeks. This $70 \%$ clearance continued after two months of maintenance therapy and this was related to once week application of zinc sulfate. This was in comparison with $2 \%$ complete clearance treated by placebo.

The mechanism of action of topical zinc sulfate is not well elucidated but most probably related to its multiple effects like antibacterial, antifungal and anti-perspirant actions.

To the best of our knowledge, this is first study carried out and showed that topical $15 \%$ zinc sulfate solution is an effective clearance of feet odor.

To keep the clearance of feet odor, we strongly advise patients to keep maintenance therapy through once application every week as shown in the present study.

Scoring of feet odor is difficult to be carried out but fortunately we invented a new scoring system that proved its practicality by the present work.

In conclusion, topical $15 \%$ zinc sulfate solution proved it's effectiveness in clearance of feet odor in $70 \%$ of patients and it had both therapeutic and prophylactic actions.

\section{REFERENCES}

[1] F. Kanda, E. Yagi, M. Fukuda, K. Nakajima, T. Ohta and O. Nakata, "Elucidation of Chemical Compounds Responsible for Foot Malodor,” British Journal of Dermatology, Vol. 122, No. 6, 1990, pp. 771-776. doi:10.1111/j.1365-2133.1990.tb06265.x

[2] K. Ara, M. Hama, S. Akiba, K. Koike, K. Okisaka, T. Hagura, T. Kamiya and F. Tomita, "Foot Odor Due to Microbial Metabolism and Its Control,” Canadian Journal of Microbiology, Vol. 52, No. 4, 2006, pp. 357-364. doi:10.1139/w05-130

[3] M. Connolly and D. de Berker, "Management of Primary Hyperhidrosis," American Journal of Clinical Dermatology, Vol. 4, No. 10, 2003, pp. 681-697. doi:10.2165/00128071-200304100-00003

[4] P. K. Lee, M. T. Zipoli, A. N. Weinberg, M. N. Swartz and R. A. Johnson, "Fitzpatrick's Dermatology in General Medicine," 6th Edition, McGraw-Hill, New York, 2003.

[5] S. A. McWilliams, I. Montgomery, D. McEwan Jenkinson, H. Y. Elder, S. M. Wilson and A. M. Sutton, "Effects of Topically Applied Antiperspirant on Sweat Gland Function,” British Journal of Dermatology, Vol. 117, No. 5, 1987, pp. 617-626. doi:10.1111/j.1365-2133.1987.tb07494.X

[6] Y. Karakoc, E. H. Aydemir, M. T. Kalkan and G. Unal, "Safe Control of Palmoplantar Hyperhidrosis with Direct Electrical Current," International Journal of Dermatology, Vo. 41, No. 9, 2002, pp. 602-605. doi:10.1046/j.1365-4362.2002.01473.x

[7] A. S. Prasad, "Zinc: The Biology and Therapeutic of an Ion,” Annals of Internal Medicine, Vo. 125, No. 2, 1996, pp. 142-143. doi:10.7326/0003-4819-125-2-199607150-00012

[8] K. E. Sharquie, A. A. Noaimi and M. M. Al-Salih, “Topical Therapy of Acne Vulgaris Using 2\% Tea Lotion in Comparison with 5\% Zinc Sulphate Solution,” Saudi Medical Journal, Vol. 29, 2008, pp. 1757-1761.

[9] K. E. Sharquie, R. A. Najim, R. K. Al-Hayani, A. A. Al-Nuaimy and D. M. Maroof, "The Therapeutic and Prophylactic Role of Oral Zinc Sulphate in Management of Recurrent Aphthous Stomatitis (RAS) in Comparison 
with Dapsone,” Saudi Medical Journal, Vol. 29, No. 5, 2008, pp. 734-738.

[10] K. E. Sharquie and K. Al-Azzawi, "Intralesional Therapy of Cutaneous Leishmaniasis with 2\% Zinc Sulphate Solution,” Pan-Arab League of Dermatologists, Vol. 7, 1996, pp. 41-46.

[11] K. E. Sharquie, R. A. Najim, D. J. Al-Timimi, I. B. Farjou, "Oral Zinc Sulphate in the Treatment of Acute Cutaneous Leishmaniasis," Clinical and Experimental Dermatology, Vol. 26, No. 1, 2001, pp. 21-26. doi:10.1046/j.1365-2230.2001.00752.x

[12] K. E. Sharquie, A. A. Khorsheed and A. A. Al-Nuaimy, "Topical Zinc Sulphate Solution for Treatment of Viral Warts,” Saudi Medical Journal, Vol. 28, No. 9, 2007, pp. 1418-1421.

[13] K. E. Sharquie and A. A. Al-Nauaimy, "Treatment of Viral Warts by Intralesional Injection of Zinc Sulphate,” Annals Saudi Medical, Vol. 22, No. 1-2, 2002, pp. 26-28.
[14] F. Al-Gurairi, M. Al-Waiz and K. E. Sharquie, "Oral Zinc Sulphate in the Treatment of Recalcitrant Viral Warts: Randomized Placebo Controlled Trial,” British Journal Dermatology, Vol. 146, No. 3, 2002, pp. 423-431. doi:10.1046/j.1365-2133.2002.04617.x

[15] K. E. Sharquie, W. S. Al-Dori, I. K. Sharquie and A. A Noaimi, "Treatment of Pityriasis Versicolor with Topical 15\% Zinc Sulphate Solution,” Iraqi Journal of Community Medicine, Vol. 21, No. 1, 2008, pp. 61-62.

[16] I. G. Al-Tereihi, “Topical 10\% Zinc Sulphate Solution in the Treatment of Superficial Fungal Infections," A Thesis Submitted to the Iraqi Board for Medical Specializations, Dermatology and Venereology, 2006.

[17] K. E. Sharquie, A. A. Noaimi and N. O. Kadir, "Topical Therapy of Xeroderma Pigmentosa with 20\% Zinc Sulphate Solution,” Iraqi Postgraduate Medical Journal, Vol. 7, No. 3, 2008, pp. 231-236. 